\title{
Revista Crítica de Ciências Sociais
}

$87 \mid 2009$

Velhos e novos desafios ao direito e à justiça

James C. Scott, The Art of Not Being Governed: An Anarchist History of Upland Southeast Asia

Rita Serra

\section{OpenEdition}

\section{Journals}

Edição electrónica

URL: http://journals.openedition.org/rccs/1603

DOI: $10.4000 /$ rccs. 1603

ISSN: 2182-7435

Editora

Centro de Estudos Sociais da Universidade de Coimbra

\section{Edição impressa}

Data de publição: 1 dezembro 2009

Paginação: 195-197

ISSN: 0254-1106

\section{Refêrencia eletrónica}

Rita Serra, « James C. Scott, The Art of Not Being Governed: An Anarchist History of Upland Southeast Asia », Revista Crítica de Ciências Sociais [Online], 87 | 2009, posto online no dia 15 outubro 2012, consultado o 22 setembro 2020. URL : http://journals.openedition.org/rccs/1603 ; DOI : https:// doi.org/10.4000/rccs. 1603 


\section{Recensões}

\section{James C. Scott (2009), The Art of Not Being Governed: An Anarchist History of Upland Southeast Asia. New Haven \& London: Yale University Press, 442 pp.}

Onze anos depois de Seeing like a State: How Certain Schemes to Improve Human Conditions Have Failed, James Scott continua a análise de como se formam os Estados e como resistem as populações a projectos de incorporação forçada. Desta vez, a história é dedicada às populações que vivem na periferia dos Estados e se governam a si mesmas.

O autor leva-nos à Zomia, uma área montanhosa do tamanho da Europa, com aproximadamente 2,5 milhões de quilómetros quadrados, que se estende pelo Vietname, Cambodja, Laos, Tailândia, Birmânia (actual Myanmar) e quatro províncias da China, até ao Nordeste da Índia. As montanhas situam-se na periferia dos Estados, e nela vivem cerca de 100 milhões de pessoas, que apresentam uma diversidade étnica e linguística notável. A Zomia representa um novo objecto de estudo e uma nova abordagem para estudar as zonas terrestres enquanto espaços políticos. Trata-se da maior região do mundo onde as populações vivem sem estarem completamente incorporadas em Estados-nações. $\mathrm{O}$ argumento apresentado é simples, mas controverso: as populações das montanhas não levam um modo de vida primitivo, anterior aos Estados. Elas são contemporâneas dos Estados, compostas por fluxos migratórios de pessoas que, ao longo dos últimos dois mil anos, escaparam aos sucessivos projectos de incorporação forçada que ocorreram nos vales. As montanhas na periferia dos Estados funcionam como zonas de refúgio, onde as populações, tirando partido das condições do terreno, conce- beram formas de subsistência e organização social para manter os Estados à distância. Por outras palavras, a localização das populações não é um dado adquirido, ela resulta de uma escolha e de um posicionamento deliberado em relação aos centros de poder vizinhos.

Vistos através desta lente que torna visível a capacidade de acção das populações, os seus modos de vida não são fruto de determinismos ecológicos ou culturais, nem são constantes ao longo do tempo. As diferentes formas de subsistência e de organização social têm uma história, e as populações materializam em práticas os seus projectos políticos.

James Scott conta-nos ao longo do livro como se constituem mutuamente os Estados e as zonas periféricas enquanto espaços agro-políticos, onde complexos de técnicas agrícolas e formas de organização social são mobilizados para manter os espaços separados, apesar de estreitamente ligados por migrações e trocas comerciais. Os espaços são constituídos como a negação do outro, com as montanhas a opor-se aos vales, os bárbaros aos civilizados, a diversidade à hegemonia, a dispersão à concentração, os que se governam a si próprios aos governados pelo Estado. A relação do centro com a periferia torna impossível compreender as histórias destes espaços políticos quando analisados separadamente.

Os sistemas agro-ecológicos compatíveis com os projectos de construção de Estados são aqueles que levam à concentração da população em torno de campos de cereais e 
possibilitam a sedentarização, propriedade privada e estruturas de poder hierarquizadas. A concentração de pessoas e excedentes agrícolas permite o controlo e monitorização das actividades a partir do centro. No Sudoeste asiático, a colheita preferida dos Estados tem sido a monocultura de arroz irrigado. Esta colheita exige mais trabalho do que outras, recorrendo a tecnologias agrícolas diferentes, como por exemplo a agricultura baseada na rotação. Mas esta última não se adequa a projectos de Estado, porque requer uma área maior de cultivo e uma população dispersa, o que funciona como uma barreira à concentração de excedentes, fiscalização e colecta de impostos. Um dos desafios dos Estados pré-modernos foi sempre o de persuadir as populações a abandonar outras formas de subsistência a fim de serem incorporadas nos projectos agrícolas e demográficos do Estado. Essa incorporação foi feita principalmente à custa da mobilização forçada de pessoas para o centro, como mão-de-obra escrava. Outro desafio foi construir sistemas legíveis e fiscalizáveis que permitissem aos funcionários do Estado controlar a população e apropriar-se da produção. Para tal, torna-se necessário construir um sistema anti-evasão a partir do centro. Além de concentrar as actividades produtivas, torná-las visíveis e ao alcance dos funcionários, o sistema usa tecnologias que possibilitam a comunicação ao longo de cadeias hierarquizadas. A escrita permite a inscrição dos registos e inventários, tais como censos e mapas cadastrais, bem como a translocação desses registos ao longo da cadeia de comando. Além disso, a escrita facilita a manutenção de estruturas hierárquicas de poder permanentes, através da inscrição de genealogias e regimes de desigualdade, continuados e baseados na propriedade.

Os projectos de construção de Estados tinham um carácter intrinsecamente experimental e acarretavam grandes riscos, com ciclos sucessivos de expansão e colapso, pontuados por epidemias, fomes e guerras. Durante a construção dos Estados pré-modernos, a periferia constituiu uma tentação constante para as populações, um lugar onde podiam estar a salvo, praticar formas alternativas de subsistência, ou realizar trocas comerciais com os vales numa base voluntária, mantendo a sua autonomia política. Para se manterem fora do alcance do Estado, as populações tiraram partido da fricção da distância e da fricção da apropriação. As zonas de refúgio são diagnosticadas pelo Estado como áreas inacessíveis, que impedem ou dificultam expedições punitivas e fiscalmente estéreis, não compensando o esforço de apropriação.

Ao estudar as formas de cultivo quanto ao seu valor de evasão nas zonas de refúgio, o autor defende que as formas de subsistência e organização social derivam em grande parte da opção de se manterem fora dos centros de poder. Por exemplo, a cultura de tubérculos (batata, inhames, cassava, entre outros) faz parte de um portfólio de colheitas resistentes à apropriação. Estas colheitas requerem pouca manutenção e podem permanecer no solo, o que torna difícil confiscá-las. O portfólio de subsistência conta com várias dezenas de espécies botânicas cultivadas, pastorícia e produtos provenientes de florestas que não existem nos vales e podem ser usados para trocas comerciais, tais como pimenta, resinas, medicamentos e ópio. As montanhas e vales ocupam nichos agro-ecológicos que se complementam.

A periferia é refúgio de uma grande diversidade de sistemas políticos e formas de organização social. Os sistemas mais simples encontram-se no nível do agregado familiar, com formas de subsistência nómadas ou técnicas que requerem pouco trabalho colectivo. A organização social é acéfala, sem chefes e sem estruturas de poder permanentes. As formas 
de organização social mais complexas nas montanhas mimetizam os Estados a escalas liliputianas. As culturas das populações são de base oral; a maioria não tem escrita, e existe heterodoxia religiosa. Ao longo do tempo, a organização social aparece como fluida e reversível, composta de unidades que se associam e dissociam consoante os projectos políticos, o posicionamento em relação a Estados vizinhos e as exigências de segurança. Os indivíduos movem-se entre formas sociais e adoptam novas identidades. Esta multiplicidade de formas de subsistência, ideologias, organização social e identidades, juntamente com a dispersão no terreno, não só mantêm o Estado à distância, como previnem a emergência de Estados no seu seio.

O projecto político de Estado é acompanhado por uma utopia civilizacional de superioridade em relação à periferia. A identidade dos "civilizados" distingue-se pelo cultivo de arroz irrigado, budismo e escrita. Os bárbaros da periferia são uma invenção social do Estado, que permite reforçar o projecto identitário da civilização através da estigmatização de outras identidades. À luz de uma análise radicalmente construtivista, a etnogénese resulta do posicionamento das populações face aos projectos políticos dos centros de poder. As populações adoptam práticas que lhes conferem graus variados de "bárbaros" ou "civilizados". As identidades étnicas não são mutuamente exclusivas, os indivíduos falam várias línguas e desafiam os sistemas de classificação dos estudiosos e funcionários do Estado. No entanto, a classificação forçada das populações em etnias pode conduzir a projectos políticos e a novas formas de relacionamento com o Estado, especialmente para reclamar direitos sobre recursos naturais ou terras. Por último, refere-se a importância política das religiões milenaristas. A promessa do fim do mundo e de uma nova ordem social onde os poderes são invertidos, anunciada por líderes carismáticos, consegue mobilizar populações com baixo nível de organização e ultrapassar os obstáculos a projectos colectivos, seja a deslocação para uma nova área ou uma revolta contra os poderes instalados.

A extensa literatura sobre a formação de Estados, tanto histórica como contemporânea, raras vezes dá atenção ao seu reverso. Esta é a história de todas as populações que escaparam a sistemas coercivos e de trabalho escravo e vivem em zonas de refúgio, desde as florestas tropicais até aos desertos, que continuam a sofrer a pressão dos Estados-nações, equipados com tecnologias que reduzem cada vez mais a distância.

Rita Serra

\section{Nelken, David (2009), Beyond Law in Context. Developing a Sociological Understanding of Law (Collected Essays in Law). Burlington: Ashgate, 320 pp.}

David Nelken é hoje uma figura académica incontornável quando se trata de problematizar a relação tensa e articulada entre direito, teoria e sociedade. Beyond Law in Context, publicado há cerca de um ano, é um livro que perde em inovação tudo aquilo que ganha em relevância no campo dos estudos sociais do direito. Perde em inovação porque se limita à compilação de um conjunto de 15 artigos que nos últimos 30 anos marcaram o essencial do seu percurso científico. Ganha em relevância porque condensa a evolução não apenas do seu esforço de teorização social das 
práticas e dos processos jurídicos, como da própria sociologia do direito enquanto área de saber investida de um objecto próprio e autonomizada epistemológica e disciplinarmente. $\mathrm{O}$ título atribuído à publicação não é irreflectido, casuístico ou produto inofensivo do jargão sociojurídico: representa uma tentativa de ultrapassar o cardápio de temas e abordagens avançados pelos manuais mais canónicos de sociologia do direito, a partir dos quais iniciou a leccionação da disciplina em meados dos anos 70. O contexto - em toda a sua espessura e polissemia sociológica (reenviando para os conceitos de ambiente, contingência ou presunção) - surgia como uma variável imperiosa que permitia pensar e despensar o direito na sua construção e dinâmica social. E nessa perspectiva mais ampla se afirmou uma bateria de autores que David Nelken procurou recensear e discutir ao longo dos diferentes ensaios presentes nesta obra, entre os quais se destacam nomes consagrados como Boyd-White, Cotterrell, Ehrlich, Fish, Habermas, Legrand, Luhmann, Pound, Teubner e Watson.

Retomam-se assim algumas interrogações elementares: cumpre o direito uma função específica na sociedade ou, pelo contrário, é-lhe constitutivo? Em que termos será possível pensar a adequação ou fidelidade entre direito e sociedade? Como compreender os efeitos e as determinações sociais, políticas e económicas num quadro de autonomia relativa do direito? Serão o discurso jurídico e o discurso sociológico narrativas insanavelmente rivais que servem formas e códigos distintos de produção de conhecimento? Será o direito em contex to uma formulação viciada ou redundante? Como sublinha o autor, "embora haja muitos e excelentes estudos sobre como o direito transforma, evita ou reprime modos alternativos de descrever e julgar a realidade social, escasseia uma teoria sobre o porquê, como e quando determinados contributos e visões sociais devem ser relevados em diferentes tipos de processos legais" (xvi). É com esta preocupação que o autor procura explorar uma terceira via entre o cepticismo e o entusiasmo relativamente à importância epistémica e capacitadora da teorização social do direito no desempenho dos operadores judiciais e na modelação da vida pública regulada e observada segundo diferentes racionalidades, onde a jurídica se combina diversa e mais ou menos hierarquicamente com outras coexistentes.

O livro arruma-se em três partes, obedecendo, grosso modo, a uma lógica simultaneamente temática, teórica e cronológica. A primeira - Only Connect - reúne quatro textos publicados entre 1981 e 1985 e procura uma problematização geral e sistematizadora da relação entre direito e sociedade. Com incidência nesta relação, são duas as culturas de investigação que se foram progressivamente consolidando: por um lado, os estudos sociojurídicos, concedendo particular enfoque às agendas de reforma institucional e desenvolvendo uma monitorização contínua do sistema jurídico, tomando para si os problemas emergentes da empiria; por outro lado, a sociologia do direito, apetrechada de um corpus conceptual e metodológico mais robusto e menos aplicado, operando a um ritmo distinto e direccionando a sua inquirição para o lugar do direito na estrutura social, por via de motivações, problemas e controvérsias teóricas relativamente autónomas e delimitadas. $\mathrm{O}$ autor elabora uma revisão histórica do desfasamento entre estas duas abordagens, procurando reformular os desafios colocados ao estudo do direito e sociedade. À margem das falácias que originaram o designado gap problem, recupera-se tanto os contributos marxistas (de Gramsci a E.P. Thompson) para pensar o direito e a reprodução social como 
outras linhas não-marxistas pertinentes para a recomposição de um programa de investigação no quadro da sociologia do direito.

A questão do desfasamento é ainda cara à relação entre direito e sociedade por razões de outra ordem: se em Roscoe Pound a reflexão sobre o direito enquanto mecanismo de controlo social levanta o problema da efectividade, em Eugene Ehrlich, mais do que instrumento, o direito é concebido como resultado e testemunho social. Pelo que o clássico contraste que o primeiro estabeleceu entre law in books e law in action - que encorajou o estudo da mudança das condições sociais sobre as quais impende a normatividade jurídica - é agora confrontado com o conceito de living law (por oposição a law for decision) proposto pelo segundo. Argumenta o autor que este conceito é mais frutuoso, permitindo ampliar e densificar o conhecimento sobre o direito na sociedade, que é assim encarado como "um aspecto da vida económica e social organicamente conectado e criado por padrões de vida comuns, trabalho e relações em grupos ou outras colectividades. Atrás da living law encontram-se as relações activas de sempre: interacção, dominação, posse e consenso, bem como os requisitos variáveis da produção e do consumo colectivos” (34). Esta abertura do pensamento normativo e da sociologia do direito à complexidade e multidimensionalidade da vida social permitiu, por um lado, reinterpretar e reavaliar a problemática da efectividade e, por outro, alimentar a pesquisa do pluralismo jurídico (à data enquadrada sobretudo pela antropologia jurídica), dando conta das tensões e da engrenagem entre múltiplas ordens normativas.

A crise da ideologia jurídica é o tópico que anima o terceiro ensaio: a uma escala macrossociológica, as transformações operadas na relação entre forma, conteúdo e função do direito são perspectivadas à luz da progressão hegemónica do neoliberalismo, da globalização da economia e do enfraquecimento dos Estados de bem-estar. Para compreender a natureza e profundidade deste processo erosivo o autor socorre-se das propostas teóricas de Jürgen Habermas no sentido de reconstituir os contornos sociojurídicos de uma mais ampla crise de legitimação experimentada nas sociedades contemporâneas. A primeira parte do livro é concluída com uma tentativa de incorporar na análise do processo legislativo e da decisão judicial os quadros conceptuais de Steven Lukes e Anthony Giddens alusivos à relação dinâmica e recíproca entre estrutura e acção social.

Repensar e reformar o paradigma dominante na sociologia do direito são os desafios - ambiciosos - assumidos na segunda parte desta publicação - Changing the Questions -, apostada numa revisão e discussão teórica através de seis artigos balizados entre 1986 e 2001 . A partir das contribuições de Stuart Henry, sublinha-se a necessidade de superar os modelos analíticos induzidos pelas designadas teorias da correspondência, isto é, do pressuposto de uma correlação automática entre a regulação jurídica e a regulação social. É aliás com esse desiderato que se explora e enfatiza o mérito de todo o trabalho precursor desse projecto epistemológico, que permitiu uma redescoberta do pluralismo normativo e forneceu "um guião estimulante para a ultrapassar um paradigma confinado aos 'efeitos' do direito na sociedade, sem abandonar o objectivo de investigar o modo como o direito contribui para a produção e a reprodução da sociedade" (94). Com o mesmo fôlego empreendedor sobre os mapas e as controvérsias teóricas da sociologia do direito, o autor desenvolve ainda uma incursão sociojurídica na teoria luhmanniana da autopoiesis, de que 
resultou uma síntese comparativa e uma clarificação conceptual entre o argumento da autonomia relativa e as características autopoiéticas do direito. Se o primeiro deriva de arrumações e especializações institucionais, ocupacionais e procedimentais, acomodando a pluralidade de interesses e requerendo um consenso político legitimador, as segundas decorrem de um processo de diferenciação funcional do subsistema jurídico, portador de um código próprio que se impõe através da sua auto-observação, de uma racionalidade dicotómica (legal/ilegal) e do recurso a mecanismos de selectividade na observação e adaptação ao ambiente externo. A exploração desta análise comparativa permite ao autor concluir que ao contrário do efeito despolitizador da autopoiesis, a autonomia relativa do direito permite um resgate do seu papel eminentemente político - apanágio dos Critical Legal Studies - face às determinações da política convencional. $\mathrm{O}$ aprofundamento do debate teórico na sociologia do direito é ainda ensaiado através do questionamento de algumas especificidades sociojurídicas do direito penal, tanto na sua relação íntima com a filosofia moral como nos termos em que se verifica a sua maior ou menor reactividade ou permeabilidade às influências externas. Já os últimos três artigos que completam a segunda parte do livro debruçam-se sobre o lugar e a construção da verdade no quadro das tensões entre direito e ciência. Tema inelutavelmente controverso, mobiliza desde logo a problemática da função pericial como recurso ilustrativo do diálogo ou da incompatibilidade entre discursos e saberes.

Se até aqui a finalidade do autor consistia em explorar e redireccionar a relação complexa e multifacetada entre direito, teoria e sociedade, a última parte do livro apresenta um conjunto de cinco artigos - publicados entre 1996 e 2007 - cuja missão é dar conta dos limites difíceis ou intransponíveis de uma sociologia do direito reflexiva. Se a viragem linguística reinsuflou a teorização social dos fenómenos jurídicos com preocupações de natureza discursiva e comunicacional - interpelando a contextualidade -, é certo que os instrumentos analíticos e conceptuais à disposição da disciplina sociológica não perderam a sua utilidade, embora nem sempre consigam apreender e decifrar o sentido jurídico dos processos sociais. Esta é, de resto, matéria controvertida e disputada entre o autor e Roger Cotterrel, que se prolonga e desdobra nos artigos finais do livro: trata-se de compreender os mecanismos através dos quais se opera uma resignificação do direito na sua dinâmica intercultural, bem como os diferentes modos de o globalizar e localizar - de que são exemplo particularmente elucidativo as idiossincrasias sociológicas do transplante jurídico.

Reunir num único livro - como outros autores o fizeram no âmbito desta Collected Essays in Law Series - dezena e meia de artigos dispersos, redigidos num intervalo de três décadas, é empresa que, mesmo para o mais coerente dos teóricos, não consegue evitar a fragmentação, ainda que a unidade de argumento seja reivindicação de partida do seu autor. O custo dessa eventual fragmentação é, no entanto, compensado pela força teórica e analítica de David Nelken e pela oferta de uma visão crítica e panorâmica sobre o mainstream e o underground da sociologia do direito. Não fornecendo uma cobertura exaustiva ou enciclopédica, esta publicação combina pedagogia com complexidade, o que lhe confere uma pertinência acrescida na compreensão da trajectória e dos desafios da relação entre direito e sociedade na contemporaneidade.

\section{Tiago Ribeiro}




\section{Martha Albertson Fineman, Jack E. Jackson, Adam P. Romero (eds.), Feminist and Queer Legal Theory. Intimate Encounters, Uncomfortable Conversations. Farnham: Ashgate, 2009, 490 pp.}

Feminist and Queer Legal Theory é uma antologia de hibridismos teóricos que premeia o desmantelamento das normas sociais, leis e estruturas patriarcais que circunscrevem a subversão do género em detrimento do sexo biológico. Em formato de pingue-pongue interdisciplinar, a antologia mapeia diferentes abordagens aos conceitos de sexo, género e sexualidade, articuladas nas últimas décadas, para configurar os termos referenciais teóricos dos debates feministas/queer. Em particular, desenrola as afirmações desenvolvidas e contestadas sobre a centralidade de uma teoria positivista da sexualidade na formulação de perspectivas críticas das instituições legais, sociais, políticas e culturais e sobre as implicações jurídicas, políticas, sociais e culturais nas distintas abordagens teóricas de género e sexualidade. Esta equação - matizada por assuntos legais da igualdade no casamento, assédio sexual, direitos dos trabalhadores e privacidade - redesenha e reimagina as alianças e antagonismos que arquitectam o feminismo e a teoria queer. O volume, com 23 académicos americanos, resulta do projecto feminista e de teoria do direito "Uncomfortable Conversation".

Nas últimas décadas, as comunidades de Lésbicas, Gays, Bissexuais e Transgéneros (LGBT) têm encarado uma constelação de triunfos e sombreado uma série de pânicos em torno da sexualidade - VIH e pânicos morais contingentes. Enquanto algumas feministas abordaram o Estado para protecção, o próprio Estado tem sido identificado como fonte substancial de perigo para as comunidades LGBT e para as mulheres. Ainda que a discriminação, com base no género, se tenha tornando inadmissível legalmente, a discriminação com base na orientação sexual permaneceu legal e afirmada: uma lésbica não poderia ser despedida do emprego por ser mulher, mas poderia por ser lésbica. Não obstante a variedade de respostas a esta situação, as que predominam nas políticas feministas, gay e lésbicas tendem a naturalizar as identidades sexuais binárias, adoptando modelos de igualdade formal que equacionam o valor moral e o estatuto político da homo- e heterossexualidade - i.e., (tentativa de) inclusão dos gays e lésbicas nos regimes de anti-discriminação existentes. É neste contexto que os teóricos queer tecem críticas às teorias feministas e às teorias gay e lésbicas. Todavia, esta colecção não é um campo de batalha entre queers e feministas; apresenta micronarrativas distintas, com questões delimitadas e específicas, bifurcadas na tentativa de negociar as linhas de pensamento.

A primeira secção, "Queer com ou sem teoria feminista do direito", introduz alguns textos-chave, posições políticas e lugares ideológico-institucionais que marcam e situam as articulações feministas e queer na contemporânea teoria do direito. A aparente e crescente tensão intelectual materializa-se na retórica de dar uma pausa ao feminismo ("taking a break from feminism”, p. 9) que faculte uma apreciação mais ampla da fluidez e ambiguidade da sexualidade e uma reconsideração das políticas da sexualidade - relegadas a questões da dependência, maternidade e/ou perigos de violência doméstica - e do prazer sexual das mulheres. Como aponta Janet Halley, a abordagem pós-moderna anti-fundacional tem conduzido ao cepticismo queer sobre a natureza, baseada na identidade, da teoria do direito e das políticas feministas. Os teóricos queer rejeitam o constrangimento 
binário e hierarquizado do hetero-/homossexual; as práticas e ideologias da "família sexual" matrimonial, descritas por Martha Albertson Fineman - forma natural de organização social e cultural da intimidade, centrada na visão patriarcal e "heteronormalizada" que privilegia a relação sexual (mesmo entre pessoas do mesmo sexo) prescrita na lei da família e nos mitos sociais; o local de trabalho "higienizado", mencionado por Vicki Schultz, e o modelo de assédio sexual - que contribuem para a desumanização do local de trabalho e assentam no falso paradigma da sexualidade, enquanto atributo individual passível de ser isolado e purgado das instituições.

A segunda secção, "Feminismo com ou sem teoria queer do direito", é uma resposta teórica à primeira. Martha T. McCluskey procura demonstrar a tendência da teoria queer para adoptar e reforçar uma perspectiva acrítica dos princípios da ideologia liberal económica, em questões relacionadas com a lei e a intimidade. Paradoxalmente, a separação - em vez da problematização - da relação entre políticas económicas e políticas de identidade, e entre mercado-Estado-família, pode reforçar as rígidas convenções da identidade e regulações da intimidade que a teoria queer quer desmantelar. Em consonância, Tucker Culbertson e Jack Jackson insistem na impossibilidade de escolher um lado na alegada divisão "feminismo versus queer". Os autores argumentam que as exclusões e colapsos dos discursos e as estruturas de subordinação, organizadas através do imaginário político liberal, juridicamente delimitado, revelam pontos teóricos e políticos muito mais relevantes e prevalentes do que os conflitos categóricos característicos das monolíticas feministas e queers. Mary Anne Case, em concordância com Margaret Mead, explora a necessidade de tabus de sexo no trabalho. Ao questionar a premissa do sexo entre pais e filhos (incesto), propõe a criação de um tabu sobre um espaço seguro - não no sentido físico de uma casa ou local de trabalho, mas o espaço transcendente de uma relação: a sacralidade de um(a) progenitor(a) com um(a) filho(a) análoga à de um(a) supervisor(a) com um(a) supervisionado(a) - que desencoraje o relacionamento de pessoas hierarquicamente relacionadas. Case procura uma solução para o problema da discriminação no local de trabalho, balanceando o argumento do tabu do incesto - que se contra-argumenta ao reprimir o erotismo e celebrar o pudor - e o argumento provocativo, de Richard Wasserstrom (1977), da irrevogabilidade da discriminação sexual e consequente desigualdade de oportunidades, até todos serem perfeitamente bissexuais. Mary Becker pondera as dinâmicas da sexualidade feminina oprimida pelo perigo (violação, assédio, incesto, violência doméstica), pela dependência, pela "maternalização" da identidade (responsabilidade da maternidade e aceitação da "repronormatividade") e pela mercantilização da ansiedade. Esta herança ideológica e cultural enfraquece uma sexualidade activa, saudável, capaz, autónoma, plena.

A terceira secção distingue algumas experiências, epistemologias e subjectividades presentes nas políticas feministas/queer. Segundo Devon Carbado, tal como as políticas tradicionais anti-racistas normalizam a heterossexualidade, as políticas dominantes gay/lésbicas marginalizam as identidades negras. Carbado desafia as noções essencialistas e reivindica intervenções anti-homofóbicas na advocacia dos direitos civis dos negros e uma intervenção anti-racista na advocacia dos direitos gay. Paisley Currah introduz as políticas dos transgéneros neste debate. A autora argumenta que os diferentes objectivos e estratégias de acção para desmantelar o género, enquanto conceito legal coerente, e para o 
expandir, de forma a incluir transgéneros, não devem ser encarados como uma proposição "e/ou". A incoerência do actual esquema de classificação dos sexos, arbitra Currah, é uma áspera ilustração da pendente incapacidade do sexo de nascença para determinar o género de um indivíduo. Kenji Yoshino examina a violência e os investimentos do discurso político-sexual que insistem em classificações binárias da sexualidade - hetero-/homo- - e na categorização diacrítica do sexo. Para Yoshino, o "contexto epistemológico" que censura a bissexualidade não é um acordo consciente entre indivíduos, mas uma norma social que se impõe inconscientemente. Cumulativamente, Elizabeth Emens, examinando os princípios e práticas da comunidade poliamor ou "não-monogamia" ética, repreende os paradoxos da lei da monogamia (no sentido legal e cultural) e do casamento.

Apesar da ideologia liberal aclamar a separação das esferas e zonas de privacidade, o direito tem sido tanto central quanto hiperactivo em comandar as normas da família, do parentesco, da intimidade e da tutela. Carlos Ball esboça uma teoria feminista de autonomia relacional para ordenar uma política de apoio e advocacia dos casamentos homossexuais, que substitua a tese do "deixa estar". Segundo o autor, quando os casais homossexuais solicitam o reconhecimento das suas relações ao Estado, não estão a pedir para serem deixados em paz, estão a pedir legitimação, logo regulação dos relacionamentos. Ruthann Robson acrescenta ao conceito de heterossexualidade compulsória, de Adrienne Rich (1980), o casamento compulsório. $\mathrm{O}$ argumento discorre uma variedade de forças que impõem, gerem, organizam, propagandeiam e mantêm à força a instituição política do casamento: tolerância da lei e benefícios económicos que favorecem pessoas casadas; forças legais e (in) directas de género e de classe (carência económica das mulheres); o paternafare de Anne Smith - instrumento burocrático da governação neoliberal que unicamente sobrecarrega mães solteiras com uma lei de dependência "heteropatriarcal" feita à medida; a prática complexa e potencialmente subversiva do processo tutelar e dos cuidadores transgressivos, questionada por Laura Kessler - i.e., tarefa de cuidar, fora do tradicional contexto familiar, por aqueles a quem o Estado, historicamente, nega o privilégio da privacidade familiar.

Esta eclética e (im)pertinente antologia coreografa as categorias (legais) das perspectivas feministas, gay/lésbicas e queers, numa dança cerimonial de conceitos iconoclastas e teses inter-relacionadas - género, identidade, sexualidade, intimidade, privacidade. O título Intimate Encounters, Uncomfortable Conversations, expõe por um lado uma noção de intimidade desconfortável que não esgota, até tipifica, o modo como estes movimentos se têm relacionado ou se poderão relacionar. Por outro, antecipa o desconforto, infligido aos leitores, da angustiante catarse de verdades calcificadas na "roda de hamster”. A afirmação foucaultiana - da sexualidade enquanto dispositivo histórico do poder, assente na inserção do sexo em sistemas de utilidade e regulação social - inscrita na teoria queer e carimbada pela teoria do devir, monta o cenário para a multiplicidade, fluidez, hibridez de sexo(s) versus categorias binárias homem/mulher, hetero-/homossexual. Este livro é a ervilha sob os 20 colchões da princesa, do conto infantil de Hans Christian Andersen A Princesa e a Ervilha.

\section{Ana Oliveira}

